\title{
VIOLÊNCIA CONTRA À MULHER E PERSPECTIVAS DE AÇÕES PROGRAMÁTICAS: O SENTIDO ESTRUTURAL DA VIOLÊNCIA DIRETA E INDIRETA ${ }^{1}$
}

\author{
Vinicius Ferreira Baptista ${ }^{2}$
}

Resumo: O artigo discute a questão da violência contra à mulher na relação entre o sentido legal e o aspecto material de ações. Procura situar a diferença entre a inscrição da violência na ordem jurídica e a necessidade de ações paralelas que atuem sobre elementos da estrutura social, ou seja, tratar a violência do princípio em que se organiza e que reincide. Ao mesmo tempo, traz ações desenvolvidas no Brasil que obtiveram sucesso na redução de reincidência da violência contra à mulher. Metodologicamente, analisamos dados estatísticos disponibilizados em estudos assim como confrontamos com bibliografia pertinente, ao passo em que cotejamos resgate das bases normativas a respeito da violência de gênero. $O$ objetivo foi discutir a necessidade de ações que incidam materialmente no sentido simbólico e prático das relações estruturadas historicamente no âmbito da violência. Assim, resgatou-se a necessidade, no âmbito das políticas públicas, da aproximação entre a compreensão simbólica da origem da violência e sua materialidade reincidente que envolve homens agressores.

Palavras-chave: gênero, violência, políticas públicas, estudos sobre gênero, violência de gênero.

\begin{abstract}
The article discusses the issue of violence against women in the relation between the legal meaning and the material aspect of actions. It seeks to
\end{abstract}

\footnotetext{
${ }^{1} \mathrm{O}$ presente trabalho é parte de projeto de pesquisa financiado no âmbito da Fundação de Amparo à Pesquisa do Estado do Rio de Janeiro - FAPERJ e da Universidade Federal Rural do Rio de Janeiro com bolsas de Iniciação Científica e Extensão, além de contar com financiamento da Coordenação de Aperfeiçoamento de Pessoal de Nível Superior - Brasil (CAPES) - Código de Financiamento 001.

${ }^{2}$ Administrador. Doutor em Políticas Públicas e Formação Humana (UERJ). Professor Adjunto do Departamento de Administração Pública e do Programa de Pós-graduação em Desenvolvimento Territorial e Políticas Públicas da Universidade Federal Rural do Rio de Janeiro (UFRRJ)
} 
situate the difference in the inscription of violence in the juridical order and the need for parallel actions that act on elements of the social structure, that is, to deal with the violence of the principle in which it is organized and that it is repeated. At the same time, it brings actions developed in Brazil that have succeeded in reducing the recurrence of violence against women. Methodologically, we analyze statistical data found in governmental and nongovernmental publications as we confront with pertinent bibliography and also with historical review of violence normative about women. The objective was to discuss the need for actions that focus materially in the symbolic and practical sense of structuralized historically relations in the scope of violence. Thus, the need, within the scope of public policies, of the approximation between the symbolic understanding of the origin of the violence and its materiality that involves aggressors.

Keywords: gender, violence, public policy, gender studies, gender violence.

\section{Introdução}

215

$\mathrm{O}$ artigo discute a questão da violência contra à mulher na relação entre o sentido legal e o aspecto material de ações. Procura situar a diferença entre a inscrição da violência na ordem jurídica e a necessidade de ações paralelas que atuem sobre elementos da estrutura social, ou seja, tratar a violência do princípio em que se organiza e que reincide. Primeiramente situamos a base normativa a respeito da violência contra a mulher, desde os primeiros códigos em que a denominação "mulher" ou "gênero" foi aplicada (também se verificou o termo "cônjuge" ou qualquer alusão ao sentido mulher/feminino. Em seguida apontamos dados estatísticos em nível nacional que vislumbra situação crítica da violência. Apontamos dados da secretaria de Políticas para Mulheres, assim como do Mapa da Violência. Por fim, destacamos iniciativas de observância de medidas conjuntas do combate à violência com o aspecto de acompanhamento do agressor. $\mathrm{O}$ objetivo, assim, foi produzir um trabalho que confronte tanto a necessidade de continuidade de políticas de caráter preventivo e punitivo de violência contra a mulher ao mesmo tempo em que se pautem políticas públicas de atuação direta no que tange acompanhamento no 
aspecto cultural, social, político e simbólico em que se carrega a violência.

A violência sofrida pelas mulheres tem proximidade com o âmbito familiar, já que $40 \%$ das mulheres brasileiras afirmam já ter sofrido violência por parte de um homem e $18 \%$ relatam sofrer ou ter sofrido violência doméstica (apud Fundação Perseu Abramo, 2010). Segundo o Mapa da Violência, de 2015, o país registrou 4.762 mortes, correspondente a taxa de 4,8 assassinatos por 100 mil mulheres e entre 2003 e 2013 o número de assassinatos de mulheres aumentou $21 \%$. Destarte a questão de raça/cor, a taxa de assassinatos de mulheres negras cresceu $19,5 \%$ (de 4,5 para 5,4 por 100 mil mulheres negras) e a de mulheres brancas caiu $11,9 \%$ (de 3,6 para 3,2 por 100 mil mulheres brancas). Situamos que em 2011, foram notificados pelo SUS 12.087 casos de estupro no país (apud Waiselfisz, 2015). Dados da Secretaria de Direitos Humanos indicam que as travestis totalizam $51 \%$ das vítimas de LGBTI-fobia no país (apud Spm, 2013). Ainda que determinadas ações e leis tenham siado criados, ainda estamos longe de ter uma violência crônica em relação às mulheres.
Leis de proteção à mulher e de penalização

$$
\text { Podemos afirmar que é após }
$$
2006, com a promulgação da Lei $\mathrm{n}^{\circ}$ 11.340, de 7 de agosto de 2006 (Chamada "Lei Maria da Penha") que temos, de fato, o início das normas jurídicas que dispõem acerca da violência e proteção à mulher. Tal lei altera a constituição, dispõe sobre a criação dos Juizados de Violência Doméstica e Familiar contra a Mulher e altera o Código de Processo Penal, o Código Penal e a Lei de Execução Penal. A violência doméstica e familiar contra a mulher constitui uma das formas de violação dos direitos humanos (Art. $6^{\circ}$ ). O Art. $7^{\circ}$ destaca formas de violência doméstica e familiar contra a mulher, entre outras: física, psicológica, sexual, patrimonial e a moral. A Lei $\mathrm{n}^{\circ} 13.641$, de 3 de abril de 2018, vem alterar a Lei Maria da Penha incluindo a tipificação do crime de descumprimento de decisão judicial que defere medidas protetivas de urgência previstas nesta Lei, cuja pena é de detenção, de três meses a dois anos. Há de se destacar que a Lei no 13.505 , de 2017, que alterou a Lei Maria da Penha, modificou a inquirição de mulher em situação de violência doméstica e 
familiar ou de testemunha de violência doméstica, quando se tratar de crime contra a mulher. As vítimas não poderão ter contato direto com investigados ou suspeitos e pessoas a eles relacionadas, além da salvaguarda da integridade física, psíquica e emocional da depoente - este último fruto das maiores críticas pela inabilidade da autoridade policial em não revitimizar a depoente. É fato que pode existir um despreparo pela autoridade policial, sobretudo do sexo masculino no trato com a vítima de violência doméstica e familiar, com a possibilidade de reprodução da violência psicológica e moral.

Não obstante, convém articular uma série de outras legislações referentes à violência contra a mulher que refinaram e ampliaram a concepção de violência em si. Muitas delas são inclusões aos códigos civil e penal, contudo, citemos as Leis em si como marco institucional. A Lei $\mathrm{n}^{\circ}$ 12.015, de 7 de agosto de 2009, reconfigura dentro do caput sobre os crimes hediondos do Código Penal o crime de Estupro como "Constranger alguém, mediante violência ou grave ameaça, a ter conjunção carnal ou a praticar ou permitir que com ele se pratique outro ato libidinoso" (Art. 213) e o crime de
Violência Sexual Mediante Fraude como “Ter conjunção carnal ou praticar outro ato libidinoso com alguém, mediante fraude ou outro meio que impeça ou dificulte a livre manifestação de vontade da vítima (Art. 215) - o que amplia a configuração do estupro e da violência sexual para além do ato sexual em si compreendendo atos libidinosos.

A Lei n ${ }^{\circ} 13.104$, de 9 de março de 2015 é a que prevê o Feminicídio como circunstância qualificadora do crime de homicídio incluindo o mesmo no rol dos crimes hediondos. A importância desta lei qualifica o homicídio de mulheres pela sua condição de sexo feminino como "atividade típica de grupo de extermínio, ainda que cometido por um só agente, e homicídio qualificado" (Art. $\left.2^{\circ}\right)$. A Lei $\mathrm{n}^{\mathrm{o}} 13.285$, de 10 de maio de 2016 destaca sobre a preferência de julgamento dos processos concernentes a crimes hediondos (Art. $1^{\circ}$ ), tendo prioridade de tramitação em todas as instâncias alterando o Código de Processo Penal. Temos também a Lei ${ }^{\circ}$ 13.642, de 3 de abril de 2018, que altera o Código Civil, acrescentando à Polícia Federal a investigação de crimes praticados por meio da rede mundial de computadores que difundam conteúdo 
misógino ou propagam o ódio ou a aversão às mulheres.

No âmbito dos mecanismos de suporte público ao combate à violência contra à mulher, temos duas leis específicas. O Decreto n ${ }^{\circ} 7.393$, de 15 de dezembro de 2010, dispõe sobre a Central de Atendimento à Mulher Ligue 180, que se trata na modalidade de serviço telefônico de utilidade pública de âmbito nacional, destinada a atender gratuitamente mulheres em situação de violência em todo o País, recebendo relatos, denúncias e manifestações relacionadas a situações de violência contra as mulheres, registrando, orientando e encaminhando à Rede de Serviços de Atendimento às Mulheres em Situação de Violência. Ao mesmo tempo, cabe informar às autoridades competentes, se for o caso, a possível ocorrência de infração penal que envolva violência contra a mulher e produzir base de informações estatísticas sobre a violência contra as mulheres, com a finalidade de subsidiar o sistema nacional de dados e de informações relativas às mulheres.

Já o Decreto no 7.958 , de 13 de março de 2013 estabelece diretrizes para o atendimento às vítimas de violência sexual pelos profissionais de segurança pública e da rede de atendimento do Sistema Único de Saúde (SUS) situando o atendimento humanizado (Art. $1^{\circ}$ ), observados os princípios do respeito da dignidade da pessoa, da não discriminação, do sigilo e da privacidade (Art. $2^{\circ}$, inciso II), informando sobre cada etapa do atendimento e a importância das condutas médicas, multiprofissionais e policiais, respeitada sua decisão sobre a realização de qualquer procedimento (Art. $2^{\circ}$, inciso IV), inclusive disponibilizando transporte à vítima de violência sexual até os serviços de referência (Art. $2^{\circ}$, inciso VII) - objetivo é evitar a revitimização da depoente em tal momento traumatizante.

Para finalizar, em termos políticos, temos a Resolução $\mathrm{n}^{\circ} 1$, de 2014 do Congresso Nacional, que dispõe sobre a criação da Comissão Permanente Mista de Combate à Violência contra a Mulher. Tal Comissão tem como parte de suas atribuições destacadas no Art. $3^{\circ}$ : o diagnóstico de lacunas existentes nas ações e serviços da Seguridade Social e na prestação de segurança pública e jurídica às mulheres vítimas de violência (inciso I), a apresentação de propostas para a consolidação da Política Nacional de Enfrentamento à Violência contra as 
Mulheres (inciso II), a realização de audiências públicas (inciso III), assim como o intercâmbio com entidades internacionais com vistas ao conhecimento de legislações, políticas e ações pertinentes ao objeto da Comissão (inciso V).

\section{Estatísticas de mortes de mulheres}

Primeiramente, convém abordar como ocorre a construção das estatísticas referentes à violência. De acordo com a Lei ${ }^{\circ} 6.015$ de 31 de dezembro de 1973, com as alterações introduzidas pela Lei $\mathrm{n}^{\mathrm{o}}$ 6.216, de 30 de junho de 1975, nenhum sepultamento pode ser realizado sem a Certidão de Óbito correspondente, lavrada no Cartório de Registro Civil, à vista da Declaração de Óbito (DO). No caso de morte por causas não naturais ou externas (suicídios, homicídios, acidentes, etc.) em localidades que contam com Instituto Médico Legal (IML), a DO deve ser preenchida, obrigatoriamente, por médico legista do IML e, em localidades sem IML, por médico investido pela autoridade judicial ou policial, na função de perito legista eventual. As DO são coletadas pelas Secretarias Municipais de Saúde, enviadas às Secretarias Estaduais e centralizadas posteriormente no Sistema de Informações de Mortalidade (SIM), da Secretaria de Vigilância em Saúde (SVS) do Ministério da Saúde (MS).

A partir de 1996, o Ministério da Saúde adotou a décima revisão da Classificação Internacional de Doenças (CID-10) da Organização Mundial de Saúde, que orientam sobre a causa da morte. Dentre as causas de óbito estabelecidas pela CID-10, foi utilizado o somatório das categorias X85 a Y09, que recebem o título genérico de Agressões Intencionais, correspondendo às tipificações de homicídios segundo às legislações de cada país, sendo também denominados como Crimes Violentos Letais Intencionais (CVLI) - constando como características básicas a presença de agressão intencional de terceiros, cujos danos ou lesões causam a morte da vítima. Dentro da categorização do CID10 podemos designar o meio ou instrumento que provocou a morte assim como apontar o local onde aconteceu o incidente.

$\mathrm{O}$ que podemos perceber, neste aspecto, é que o Brasil carece de base estatística das áreas de segurança e de justiça no que se refere às denúncias, processos e sentenças sobre as diversas formas de violência contra as mulheres. 
Não há base robusta para a criação de mecanismos de acompanhamento estatístico sobre dados tendo como base a estratificação social. Tal proposta permitiria estudos qualitativos, aperfeiçoando ou organizando novas políticas públicas objetivando o enfrentamento da violência de gênero contra as mulheres.

Não obstante, esta não diferenciação trata a violência de forma homogênea, essencializando a categoria "mulher", desconsiderando atos vis em termos de raça/etnia/cor, renda, classe social, escolaridade, localidade e gênero. Mulheres transexuais e travestis, por exemplo, também são desconsiderados totalmente destas análises. Temos então a invisibilidade de corpos (apud Butler, 1999; apud Davis, 1983), mais uma violência - neste caso simbólica, mas também real e potencial, pois, ao desconsiderar estes corpos, negligencia o fato de sua existência e qualquer possibilidade de criação de mecanismos de prevenção e combate à violência. Trata-se da dupla violência: a ilegal, mediante às formas de violência de um agente particular; e a legal, por meio da violência estatal, legalizada e legitimada pela invisibilidade, quiçá, proposital.
Esta dupla violência estatal condiciona na perspectiva das diferentes formas de opressão e legitimação da violência, os mecanismos de sua perpetuação e, em certa medida, justificativa e justificação. Há de se considerar que a negligencia constrói narrativas e o senso de impunidade, ao mesmo tempo em que incentiva a compreensão de desvalorização do corpo e do delito cometido, em uma perspectiva de institucionalização de formas de violência que organizam mecanismos de produção e reprodução na ordem social - assim como na negligencia da norma jurídica (apud Young, 1997, 2011).

A nível internacional, o Brasil, dentre 83 países analisados, aparece com o $5^{\circ}$ lugar dentre as taxas de homicídios de mulheres anualmente. Tal perspectiva situa uma posição 48 vezes mais mortal que o Reino Unido, 24 vezes mais que Irlanda e 16 vezes mais que o Japão (apud Waiselfisz, 2015). Podemos assim indicar que o Brasil configura um dos países mais perigosos para as mulheres.

Segundo os dados do Mapa da Violência de 2015, entre 1980 e 2013 , morreu um total de 106.093 mulheres, vítimas de homicídio, passando de 1.353 mulheres em 1980, para 4.762 em 2013 
(configurando aumento de 252\%). Com uma taxa de 2,3 vítimas por $100 \mathrm{mil} \mathrm{em}$ 1980 para 4,8 em 2013 (aumento de 111,1\%). Entre 1980 e 2006, antes da sanção da Lei Maria da Penha, o aumento do total de homicídios de mulheres variou $197,3 \%$ com variância de taxa de homicídio de mulheres em $87,7 \%$. A partir da sanção da referida Lei, o crescimento do total de homicídios de mulheres variou 18,4\% com variância de taxa em 12,5\%. Entre 1980 e 2006, o crescimento do número de homicídios de mulheres foi de 7,6\% ao ano com taxa de homicídio de mulheres em $2,5 \%$ ao ano. Já após 2006, com a vigência da Lei, o crescimento do número desses homicídios cai para $2,6 \%$ ao ano e o crescimento das taxas cai para $1,7 \%$ ao ano (apud Waiselfisz, 2015).

Neste contexto, após a sanção da Lei ${ }^{\circ} 11.340 / 2006$, as variações do total de homicídios e das taxas caem abruptamente em termos de crescimento - isso não significa que as mulheres não estejam morrendo, pelo contrário, mas que as mesmas vêm morrendo em menor variância e expressão devido às tipificações de crimes e, sobretudo, legislação referente aos crimes de violência, além da criação de programas de apoio e acompanhamento às denúncias das vítimas.

O que podemos apreender do Mapa da Violência de 2016, é que a partir da promulgação da Lei Maria da Penha é que as taxas de mortalidade, assim como o total de homicídio de mulheres começam a ter incidência menor de crescimento. As taxas possuem crescimento em média de um terço relativo ao período ao ano de 2006 e o total de homicídios cresce em ritmos de quase metade em relação ao mesmo período de 2006. Não podemos também nos enganar nos números, tendo em vista que, em termos absolutos, a proporção de mulheres em 1980 era inferior ao quantitativo atual, assim, devemos considerar a proporcionalidade referente à taxa populacional.

Há, de fato, uso da Lei Maria da Penha e mecanismos associados que incidem sobre tal questão. A tipificação do crime de violência doméstica e a conjuntura que a envolve, assim como a possibilidade de prisão e de medidas cautelares e protetivas, a construção de bancos de dados além do estímulo à denúncia (que visibilizou o crime) também são aspectos que permitem analisar os dados. Em certa medida, podemos argumentar que a violência 
contra à mulher continua crescendo, ainda que em ritmos menores, contudo, crescem em escalas menores - e este aspecto é que se deve considerar. Como demonstrado, a tendência de aumento das mortes era evidente até o momento da promulgação da Lei Maria da Penha.

No que se referem às taxas de mortalidade por Unidade de Federação, alguns aspectos são válidos. Do total de mortes, as Regiões Nordeste, Sul, Centro-Oeste e Norte foram as regiões, respectivamente, que mais registraram mortes de mulheres em 2013, sendo os Estados de São Paulo, Minas Gerais, Bahia e Rio de Janeiro, respectivamente, os que mais tiveram casos de morte registrados no mesmo ano. No período de 2003 a 2013, apenas a Região Sudeste registrou queda de morte de mulheres, especificamente o estado de São Paulo, que reduziu em tal período quase $39,7 \%$ (apud Waiselfisz, 2015).

Quanto às taxas de mortalidade, $\mathrm{o}$ estado de Roraima é o que mais registrou mortes em 2013, 15,3\% de mulheres, sendo que entre 2003 e 2013, tal estado cresceu, em taxa de mortalidade $343,9 \%$ - a região Norte cresceu à taxa de mortalidade em 75,8\% de 2003 a 2013. Já a região centro-oeste é a que tem o maior percentual de aumento de taxas, sendo 7,0\% em 2013. O estado da Paraíba teve uma variação entre 2003/2013 de 229\% já Bahia teve $159,3 \%$ e, especificamente, todos os estados das regiões Norte e Nordeste aumentaram as taxas percentuais de mortes de mulheres.

Há de se considerar que as taxas nacionais de homicídios enganam e não expressam a vulnerabilidade. O Brasil apresentava taxas de homicídio de mulheres por 100 mil em 2013 da ordem 4,8\% assim, temos 20 estados acima (sendo que em 5 deles quase o dobro da média nacional), 1 no mesmo patamar e 7 abaixo. Roraima apresenta o triplo da média o que demonstra que há grau de vulnerabilidade expressivo da mulher no âmbito brasileiro. Contudo, ainda de acordo com o Mara da Violência, Rondônia, Espírito Santo, Pernambuco, São Paulo e Rio de Janeiro apresentaram quedas no ano de 2013 em termos das taxas (apud Waiselfisz, 2015). Especificamente, não podemos desconsiderar esta questão de que 20 estados (2/3 das unidades de federação), a maioria nas regiões Norte e Nordeste, apresenta índices acima da média nacional - o que implica uma situação de vulnerabilidade crônica que atinge a nível nacional exigindo, assim, políticas 
públicas, tanto setoriais, quanto gerais, a fim de que se reconfigure as perspectivas de vida das mulheres.

No quesito municipalidade, dentre os 100 municípios com mais de 10 mil habitantes do sexo feminino com as maiores taxas médias de homicídio de mulheres (por 100 mil) não temos nenhuma capital. E dos 1.627 municípios com maior volume de população feminina em $637 \quad(39,2 \%)$ não foi registrado nenhum homicídio feminino no ano de 2013 e em 122 (7,5\%) não foi registrado nenhum homicídio feminino nos últimos 5 anos disponíveis (2009 a 2013). Há de se considerar que os municípios com as maiores taxas de assassinato de mulheres são os de pequeno porte. Os 100 municípios com as maiores taxas médias no quinquênio foram responsáveis por 429 homicídios femininos do total de 22.252 registados no período de 2009 a 2013 (menos de 2\%). Já na ótica masculina ocorre o inverso: os 100 municípios com as maiores taxas concentram $16,7 \%$ do total de homicídios do País (apud Waiselfisz, 2015).

A noção de sujeito de justiça (apud Fraser, 2009) permite considerarmos as dificuldades de se trabalhar quando não existem medidas públicas de igualdade social, política e moral - neste ponto, significa que dentro da ordem brasileira, possuímos discrepâncias entre sujeitos de justiça plenos de direitos e capacidades de existência (apud Butler, 2016).

Quando entramos no quesito "Cor" observamos que as taxas de homicídios das mulheres brancas caíram (11,9\%: de 3,6 por 100 mil brancas, em 2003, para 3,2 em 2013), as negras aumentaram (19,5\%, passando, nesse mesmo período, de 4,5 para 5,4 por 100 mil), especificamente no âmbito de 7 estados, no Distrito Federal e no Brasil. Em 2003 morriam assassinadas 22,9\% mais negras do que brancas. Já em 2013 observamos este índice chegar em 2013, a 66,7\% (apud Waiselfisz, 2015). Destacamos também que em 13 estados as mortes de mulheres sobem independentemente de cor sendo que o estado do Rio Grande do Sul é o único em que se tem mais mortes de brancas e redução das mortes de negras).

Alguns dados são ainda pertinentes: o infanticídio (12 a 18 anos) feminino vem crescendo (passando de $0,4 \%$ a $3,3 \%$; dentre 18 a 30 anos flutuou de $3,6 \%$ a $3,4 \%$ (destacando a domesticidade, ou seja, a concentração da morte relacionada ao ambiente 
familiar e à residência); acima de 33 anos, com relativa queda de $2,4 \%$ a $0,1 \%$. Os meios aplicados têm preferência pela arma de fogo $(48,8 \%)$ em seguida os materiais cortantes $(25,3 \%)$ sendo que homens são mortos por arma de fogo $(73,2 \%)$. Já o local, as mulheres morrem mais em vias públicas $(31,2 \%)$, domiciliar $(27,1 \%)$ e em estabelecimentos de saúde $(25,2 \%)$ sendo eu os homens são mortos na maioria em vias públicas $(48,2 \%)$ (apud Waiselfisz, 2015).

Esta perspectiva aponta considerar que homens e mulheres não possuem as mesmas condições de vida e usufruto de liberdade e segurança, sendo as mulheres prejudicadas em termos de vulnerabilidade em todas as suas formas. Consideramos assim, a afirmativa de que as mulheres não vivem - mas sobrevivem aos contextos de violência aos quais estão sujeitas. Violências institucionalizadas, regradas socialmente, amparadas na ordem moral e social, legitimadas por contextos masculinizantes, patriarcais e senhoriais que assujeitam mulheres à perspectiva subalterna da mera existência inferior e,

\footnotetext{
${ }^{3}$ Podemos indicar que Davis (2014) e Okin (1989), trabalham estas perspectivas.
}

em certa medida líquida ${ }^{3}$. Não obstante, há diferença entre as diferenças, ou seja, há vulnerabilidade entre as vulnerabilidades - não que uma seja mais opressora que a outra, ou que acumulassem em si a opressão, mas que a base da opressão funciona estruturalmente quando observamos a questão das mulheres pretas e pardas, sobretudo em zonas sociais vulneráveis.

\section{Medidas protetivas para além da violência direta}

A Constituição Federal brasileira de 1988 destaca, em seu Art. 226, §8, que “O Estado assegurará a assistência à família na pessoa de cada um dos que a integram, criando mecanismos para coibir a violência no âmbito de suas relações". Contudo, a ordenação da violência contra à mulher está dispersa em inúmeras bases normativas, desde em aspecto criminal, civil, passando pela organização de poderes e instituições sociais, além de programas específicos. Assim, tentaremos sumarizar algumas destas bases neste texto. 
Se há progresso, há também regresso no que toca à Cidadania, em termos de distribuição de Direitos e exercício dos mesmos. No sentido de que, ao mesmo tempo em que surgem processos políticos e institucionais que proliferam e insurgem participações democráticas, institucionais ou não, formais ou não, existe "um emaranhado entre a democracia e seus opositores", em que surgem novos tipos de cidadãos e, paralelamente, novas formas de violência e exclusão que a corroem (Houlston, 2010: 21). Um processo de mão dupla, onde o alcance de novos direitos e exercício de cidadania acaba sendo percebido como perigoso ao exercício de poder de determinados grupos que, ao ver isso como perda de privilégios, entende que tal processo deve ser combatido.

Em observância ao Decreto-Lei $\mathrm{n}^{\text {o }} 3689$ de 3 de outubro 1941, que organiza o Código de Processo Penal, comecemos pelo Art. 292, parágrafo único, o qual destaca a proibição do "uso de algemas em mulheres grávidas durante os atos médico-hospitalares preparatórios para a realização do parto e durante o trabalho de parto, bem como em mulheres durante o período de puerpério imediato". Já o Art. 313, observando o Art. 312, admite a prisão preventiva em casos de o crime "envolver violência doméstica e familiar contra a mulher, criança, adolescente, idoso, enfermo ou pessoa com deficiência", como base de medida protetiva. Quando a mulher for objeto de prevenção preventiva, o Art. 318 destaca a sua possível substituição quando envolver gestantes ou mulher com filho de até 12 (doze) anos de idade incompletos. Há de salientarmos que tais ordenamentos não estavam previstos na redação da lei original, assim o Art. 292 teve sua Redação alterada pela Lei $n^{\circ}$ 13.434, de 2017, o Art. 313 pela Lei ${ }^{\circ}$ 12.403, de 2011 e o Art. 313 pela Lei no 13.257, de 2016, dentro do Código de Processo Penal.

No âmbito da Lei n ${ }^{\circ} 13105$ de 16 de março 2015, que organiza o Código de Processo Civil, temos o Art. 528 que dispõe sobre cumprimento de sentença que reconheça a exigibilidade de obrigação de prestar alimentos, com possibilidade de prisão pelo não pagamento, sendo a sua execução destaca pelo Art. 911 e Art. 912, que permite "o desconto em folha de pagamento de pessoal". Tais dispositivos, tendo em vista, o caso de a guarda de crianças permanecerem com a 
mãe, ter-se a segurança para o pagamento dos alimentos sendo que, no caso do Art. 912, permite maior segurança pelo desconto direto. Não podemos esquecer também da Lei $\mathrm{n}^{\circ}$ 9.099, de 26 de setembro de 1995, que sobre os Juizados Especiais Cíveis e Criminais. Na referida lei, as chamadas "pequenas causas", ou seja, "as causas cujo valor não exceda a quarenta vezes o salário mínimo", permite maior celeridade e economia processual, muitas vezes sem a necessidade de advogados e permitindo conciliação.

Já, especificamente sobre o Código Civil, Lei n ${ }^{\circ} 10.406$ de 10 de janeiro 2002, existem alguns aspectos absurdos que demonstram desigualdade de gênero no âmbito das mulheres dentro do Código Civil, a exemplo da possibilidade do registro de casamento civil para viúvas somente após dez meses depois do começo da viuvez, ou da dissolução da sociedade conjugal, em caso de nulidade do casamento ou viuvez, segundo o Art. 1.523, Inciso II tal aspecto não existe para homens.

No âmbito do Código Penal, Decreto-Lei $n^{\circ} 2.848$, de 7 de dezembro de 1940, no caso de violência contra a mulher e mulheres grávidas, o Art. 61, Inciso I, alínea $\mathrm{F}$ e $\mathrm{H}$, permitem agravar
226

a pena, quando não constituir ou qualificar o crime. Dentro do Código Penal, temos o Feminicídio, incluído pela Lei $\mathrm{n}^{\mathrm{o}}$ 13.104, de 2015, pela tipificação caracterizada como crime contra à vida da mulher "por razões da condição de sexo feminino", sendo que as condições envolvem "violência doméstica e familiar" (inciso I) e “menosprezo ou discriminação à condição de mulher" (inciso II). Também temos, dentro do Caput de Lesão Corporal, o crime de Violência Doméstica, Art. 129, $\S 9^{\circ}$, tipificado como lesão praticada "contra ascendente, descendente, irmão, cônjuge ou companheiro, ou com quem conviva ou tenha convivido, ou, ainda, prevalecendo-se o agente das relações domésticas, de coabitação ou de hospitalidade" - este último crime foi alterado pela redação da Lei $n^{\circ} 11.340$, de 2006 (Lei Maria da Penha).

O Art. $2^{\circ}$ situa que toda mulher "goza dos direitos fundamentais inerentes à pessoa humana, sendo-lhe asseguradas as oportunidades e facilidades para viver sem violência" e o Art. $3^{\circ}$ obriga ao Estado assegurar "às mulheres as condições para o exercício efetivo dos direitos". O Art. $5^{\circ}$ configura violência doméstica e familiar contra a 
mulher "qualquer ação ou omissão baseada no gênero que lhe cause morte, lesão, sofrimento físico, sexual ou psicológico e dano moral ou patrimonial", sendo que as relações pessoais enunciadas neste artigo independem de orientação sexual. A violência doméstica e familiar contra a mulher constitui uma das formas de violação dos direitos humanos (Art. $6^{\circ}$ ). $\mathrm{O}$ Art. $7^{\circ}$ destaca formas de violência doméstica e familiar contra a mulher, entre outras: física, psicológica, sexual, patrimonial e a moral.

O Art. 22 destaca que "constatada a prática de violência doméstica e familiar contra a mulher, nos termos desta Lei, o juiz poderá aplicar, de imediato, ao agressor, em conjunto ou separadamente, as seguintes medidas protetivas de urgência" entre elas o afastamento do lar, domicílio ou local de convivência com a ofendida (inciso II), a proibição da aproximação e contato da ofendida, de seus familiares e das testemunhas (inciso III, alíneas A e B) e a restrição ou suspensão de visitas aos dependentes menores (inciso IV). A Lei $n^{\circ} 13.641$, de 3 de abril de 2018, vem alterar a Lei Maria da Penha incluindo a tipificação do crime de descumprimento de decisão judicial que defere medidas protetivas de urgência previstas nesta Lei, cuja pena é de detenção, de três meses a dois anos.

Entre as medidas integradas de prevenção, o Art. $8^{\circ}$, além de situar a integração operacional do Poder Judiciário, do Ministério Público e da Defensoria Pública com as áreas de segurança pública, assistência social, saúde, educação, trabalho e habitação, situa a promoção de estudos e pesquisas, estatísticas e outras informações relevantes, com a perspectiva de gênero e de raça ou etnia, concernentes às causas, às consequências e à frequência da violência doméstica e familiar contra a mulher, para a sistematização de dados, a serem unificados nacionalmente, e a avaliação periódica dos resultados das medidas adotadas. Não obstante, o mesmo artigo destaca a implementação de atendimento policial especializado para as mulheres, em particular nas Delegacias de Atendimento à Mulher e a promoção e a realização de campanhas educativas de prevenção da violência doméstica e familiar contra a mulher, voltadas ao público escolar e à sociedade em geral.

Um dos artigos relevantes no âmbito da segurança econômica das mulheres está no Art. $9^{\circ}, \S 2^{\circ}$ inciso II, no 
qual juiz assegurará à mulher em situação de violência doméstica e familiar, para preservar sua integridade física e psicológica a "manutenção do vínculo trabalhista, quando necessário o afastamento do local de trabalho, por até seis meses". O Art. $10^{\circ}$, o atendimento pela autoridade policial se dará preferencialmente do sexo feminino nos casos de violência doméstica e familiar contra a mulher.

Há de se destacar que a Lei $\mathrm{n}^{\circ}$ 13.505, de 2017, que alterou a Lei Maria da Penha, modificou a inquirição de mulher em situação de violência doméstica e familiar ou de testemunha de violência doméstica, quando se tratar de crime contra a mulher. As vítimas não poderão ter contato direto com investigados ou suspeitos e pessoas a eles relacionadas, além da salvaguarda da integridade física, psíquica e emocional da depoente - este último fruto das maiores críticas pela inabilidade da autoridade policial em não revitimizar a depoente. É fato que pode existir um despreparo pela autoridade policial, sobretudo do sexo masculino no trato com a vítima de violência doméstica e familiar, com a possibilidade de reprodução da violência psicológica e moral.
O Ministério Público, segundo o Art. $25^{\circ}$, intervirá, quando não for parte, nas causas cíveis e criminais decorrentes da violência doméstica e familiar contra a mulher. Assim como pela Lei $\mathrm{n}^{\circ} 7.210$, de 11 de julho de 1984 (Lei de Execução Penal), "Nos casos de violência doméstica contra a mulher, o juiz poderá determinar o comparecimento obrigatório do agressor a programas de recuperação e reeducação" (Art. 152, parágrafo único). No âmbito da Defensoria Pública, a Lei Complementar $\mathrm{n}^{\circ} 80$, de 12 de janeiro de 1994, uma de suas funções institucionais está a de "exercer a defesa dos interesses individuais e coletivos [...], da mulher vítima de violência doméstica e familiar e de outros grupos sociais vulneráveis que mereçam proteção especial do Estado" (inciso XI, Art. $4^{\circ}$ ).

Não obstante à criação da Lei $n^{\circ}$ 11.340, de 7 de agosto de 2006 (Lei Maria da Penha), as ações que observassem medidas que reintegrassem agressores de mulher começam a ter aplicações apenas a partir de 2016 com iniciativas locais, sobretudo das polícias militares ou guardas municipais de determinados estados e municípios brasileiros. Tal configuração reflete, em primeiro momento, o sentido punitivo 
direto das agressões contra às mulheres, um problema crônico estrutural da história brasileira. Em um segundo momento reflete a não preocupação ou, em certa medida, a visão reducionista de que problemas de violência são eliminados pela ação direta da violência - pela ação material de proibição do ato violento.

Esta configuração que distancia o ato direto da violência física do ato simbólico, possivelmente indireto, dos atos psicossociais da violência, não necessariamente constrói políticas públicas efetivas que atuem diretamente na eliminação do ato violento. A ação violenta e física da violência envolve caráter psicológico, social, emocional, político, histórico, econômico, dentre outras perspectivas e que apenas no combate direto proibitivo da violência de caráter físico não é capaz de eliminar substancialmente a violência em si, pois ela fica carregada em caráter das relações sociais.

As primeiras medidas legislativas em âmbito nacional decorrem do ano de 2016 com o Projeto de Lei do Senado $n^{\circ}$ 9, de 2016, de autoria da Comissão de

\footnotetext{
${ }^{4}$ Ver a tramitação completa do Projeto de Lei $\mathrm{n}^{\circ}$ 5.001/2016 em $<$ https://www.camara.leg.br/proposicoesWe
}

Direitos Humanos e Legislação Participativa que "Acrescenta inciso V ao art. 23 da Lei $\mathrm{n}^{\circ} 11.340$, de 7 de agosto de 2006 (Lei Maria da Penha), para estabelecer, como medida protetiva de urgência à ofendida, a frequência do agressor a centro de educação e de reabilitação". Esta inclusão não observou quais medidas de fato seriam incluídas nesta lei. Entre construções legislativas nas casas legislativas, este projeto de Lei encontra-se atualmente no Senado para discussão e posterior encaminhamento à Câmara dos Deputados no âmbito do Projeto de Lei da Câmara dos Deputados nº 5.001 de $2016^{4}$.

Não obstante, a questão da Educação aqui alcança elementos tanto na perspectiva formal quanto informal. A legislação é elemento crucial no ordenamento das relações, contudo, ela se pauta preferencialmente pelo elemento reativo, quando provocada pela interrupção na "normalidade", ou seja, quando há rompimento da prescrição daquilo o que seria conhecido como o padrão esperado de comportamento - no caso, a não violência. Aqui há relevância

b/prop_mostrarintegra?codteor $=1450172 \& \mathrm{f}$ ilename $=P L+5001 / 2016>$. Acesso em 16 de julho de 2019 
no ensino formal, onde projetos políticopedagógicos de cursos nos vários níveis formais podem construir sujeitos que observem as desigualdades sociais e se pautem pelo confronto das mesmas, o que, em certo sentido, é propositivo e se organiza pelo conhecimento e enfrentamento das estruturas opressoras (apud Baptista, 2017; apud Baptista e Santos). Assim perspectivas de desigualdades sociais que sejam incorporadas como projetos políticos no ensino permitem construir tanto sujeitos de justiça (apud Fraser, 2009) quanto sociedades engajadas não no sentido reativo, porém propositivo e proativo.

De forma substantiva e material programática, apenas em 2018, de iniciativa da Câmara dos Deputados, temos o projeto de lei n. ${ }^{\circ} 10.593$, de 2018 que instituiria o Programa Tempo de Despertar, que disporia sobre a reflexão, conscientização e responsabilização dos autores de violência doméstica e grupos reflexivos de homens ${ }^{5}$. Aqui, temos um projeto de lei que é direto no sistema propositivo de ações concretas de ressocialização de homens agressores. Há de se destacar que o programa teria

\footnotetext{
${ }^{5}$ Sobre o Projeto de Lei no 10.593 da Câmara dos Deputados, ver em $<$ https://www.camara.leg.br/propostas-
}

como uma de suas bases "a transformação e rompimento com a cultura de violência contra as mulheres, em todas as suas formas e intensidades de manifestação", a "desconstrução da cultura do machismo" e, sobretudo, "promover um ambiente reflexivo que favoreça a construção de alternativas à violência para a resolução de problemas e conflitos familiares". Este projeto de lei baseava-se na Lei do Estado de São Paulo de $\mathrm{n}^{\circ} 16.732$, de 1 de novembro de 2017 que instituiu um programa semelhante, em nível municipal. Infelizmente, este Programa Tempo de Despertar foi rejeitado e incluído de forma global na proposta do Projeto de Lei do Senado $\mathrm{n}^{\circ}$ 9, de 2016 que, ao fim, não observava esta questão geral de criação de programa específico, mas orientava apenas a norma geral em nível nacional e que, posteriormente, seria reinscrito nas medidas locais em estados e municípios brasileiros.

Em termos substantivos de ações concretas, temos iniciativas da Cidade de São Paulo, em nível local ou municipal. O Projeto "Guardiã Maria da Penha" foi criado pelo Decreto Municipal no 55.089

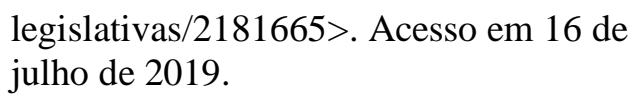
legislativas/2181665>. Acesso em $16 \mathrm{de}$ julho de 2019. 
em 08 de maio de 2014. Com a sanção da Lei municipal $\mathrm{n}^{\circ} 16.165$ de 13 de abril de 2015, o Programa passa a integrar uma política de estado ${ }^{6}$. O Programa prevê proteção às mulheres vítimas de violência doméstica, com medidas garantidas pela Lei Maria da Penha através da atuação da Guarda Civil Metropolitana e da Secretaria Municipal de Políticas para as Mulheres. Tem por objetivo combater a violência física, psicológica, sexual, moral e patrimonial contra as mulheres, monitorar o cumprimento das normas penais que garantem sua proteção e a responsabilização do agressor, além de proporcionar acolhida humanizada e orientação às vítimas quanto aos serviços municipais disponíveis. A iniciativa é fruto de uma colaboração entre a Secretaria Municipal de Segurança Urbana (SMSU), a Secretaria Municipal de Políticas para as Mulheres (SMPM) e o Ministério Público do Estado de São Paulo, através do Grupo de Atuação

\footnotetext{
${ }^{6}$ Mais informações do programa podem ser encontradas em $<$ https://www.prefeitura.sp.gov.br/cidade/se cretarias/seguranca_urbana/acoes_especiais /index.php? $\mathrm{p}=179864>$. Acesso em $16 \mathrm{de}$ julho de 2019.

${ }^{7} \mathrm{O}$ projeto detalhado pode ser encontrado em

<http://www.pmerj.rj.gov.br/2015/11/projet
}

Especial de Enfretamento à Violência Doméstica (GEVID). O Programa teve seu início em 06 de junho de 2014. No período de 06/06/2014 a 28/02/2019, foram realizadas 48.071 (Quarenta e oito mil e setenta e uma) visitas pela equipe da Guardiã Maria da Penha, sendo o total de 1437 casos atendidos até março de 2019. Há de se destacar a redução de reincidência de agressão contra mulheres de $65 \%$ para $2 \%$ após a aplicação das medidas.

Em nível estadual ou médio, temse no Estado do Rio de Janeiro o programa Guardiões da $\mathrm{Vida}^{7}$, que fazem visitas periódicas à casa das vítimas para fiscalizar cumprimento de medidas protetivas pelo agressor. Trata-se de um programa da Polícia Militar do Rio de prevenção à violência doméstica. De 823 vítimas que ingressaram no programa em 2017, 647 já haviam sofrido agressões anteriores. Após o acompanhamento dos guardiões, a reincidência desabou de $78,61 \%$ para $3,4 \%$ dos casos $^{8}$. Em 2018,

o-guardioes-da-vida-10o-bpm/>. Acesso em 16 de julho de 2019.

${ }^{8}$ Dados podem ser encontrados em <https://oglobo.globo.com/rio/celina/progra ma-da-policia-militar-reduz-de-7861-para34-reincidencia-da-violencia-contramulher-23508115> e no Dossiê Mulher, do Instituto de Segurança Pública do Estado do Rio de Janeiro em 〈https://isp.rj.gov.br>. Acesso em 16 de julho de 2019. 
do total de mulheres acompanhadas, 28 voltaram a sofrer alguma agressão por parte do companheiro. A Polícia Militar é responsável pelo policiamento preventivo das ruas, contudo, a maioria das agressões contra as mulheres acontece dentro de casa. Neste contexto, os policiais vinculados ao Programa atuam em duplas formadas por um homem e uma mulher e recebem treinamento específico, como cursos de mediação de conflitos, para acompanhar tanto a vítima quanto o agressor. Tratase de alcançar a violência doméstica ao reduto do ambiente familiar, costumeiramente reservado e que acaba por esconder a violência de fato.

O que podemos observar destas duas medidas locais é que elas vêm alcançando outros estados e municípios brasileiros. Há discussões sendo levantadas no Estado da Bahia, por exemplo ${ }^{9}$. Para além de medida apenas jurídica que tipifique o ato infrator no arcabouço jurídico justificando e medindo penalizações ao homem agressor (apud Rhode 1991; apud Cornell 1998), é preciso também que se

\footnotetext{
${ }^{9}$ O Ministério Público e a Secretaria de Estado de Segurança vêm criando debates acerca de programa nos moldes do desenvolvido pela Cidade de São Paulo.
}

inscreva na ordem cultural, social, econômica e política como esta violência se relaciona, uma vez que não se trata de violência vazia de sentido, porém carregada de materialidade que se perpetua no tempo, em sentido geracional e cultural das práticas (apud Bourdieu 1998; apud Butler 1999).

Esta violência se desenvolve de forma estrutural e sistêmica alcançando espaços silenciosamente e assentida como normalizada nas hierarquias das práticas cotidianas e que atua também de forma diferencias entre classes sociais, raças e gênero (Collins 1990; Hooks 1984). Ainda assim, esta violência se configura como uma medida estrutural que organiza processos e medidas que sustentam sentidos opressores uns aos outros e que, tendo em vista seu caráter sistêmico e estrutural, ações que negligenciam tal caráter são fadadas ao fracasso. Não se escolhe quais processos opressores sofrer em dado momento - a violência contra a mulher estrutura uma rede que organiza o rebaixamento de forma legitimada que afasta elementos

\footnotetext{
Ver mais em

$<$ http://www.al.ba.gov.br/midiacenter/noticias/32678>. Acesso em 16 de julho de 2019 .
} 
de igual valor moral (apud Young, 1997, 2011; apud Davis, 1983).

\section{Considerações finais}

A questão da violência contra mulher requer medidas que se voltem ao caráter cultural, simbólico, psicológico, social e, sobretudo, histórico que se entrelaçam nas relações de violência de gênero. A violência que ocorre em âmbito doméstico, especificamente, a que ocorre no ambiente familiar, percorre relações patriarcais, hierárquicas e inferiorizantes, que deterioram o potencial das mulheres de serem vistas como sujeitos de justiça, impedindo-as de estar como sujeitos de igual valor moral nas várias esferas da vida (apud Fraser, 1989, 2009).

Políticas públicas, assim, precisam ter materialidade histórica, observar os contextos que envolvem o sentido mais amplo de resolubilidade de problemas críticos criados na estrutura social. Violência contra a mulher não é mero ato físico, mas ato organizado de sentidos que põem à frente seu sentido legitimador das diferenças hierarquizadas. Gênero é conceito analítico, mas também histórico e político para se situar medidas de caráter público que criem possibilidade de rupturas de contextos de desigualdade estrutural (apud Okin 1989; apud Pateman 1998; apud Phillips 2011).

Por fim, vemos que, no âmbito brasileiro, ainda há muito o que se percorrer no sentido de proteção às mulheres no que se referem às medidas de combate à violência de gênero. $\mathrm{O}$ espaço temporal da criação de uma Lei que tipifica a violência doméstica (2006) à criação de outra Lei que tipifica como caráter mais penalizante o homicídio de mulheres (2015) para o debate de medidas que ressocializem ou reintegrem homens agressores (2016) é de dez anos, ou seja, da proteção à mulher e penalização dos agressores até o início do debate de medidas que incidam diretamente sobre os sentidos simbólicos e culturais desta violência, tem-se um lapso temporal significativo em que se poderia ter criado um conjunto de medidas mais intensivo e que procurasse a ruptura da violência em seu sentido estrutural: na História, na Política, nas relações culturais e sociais. Este lapso aponta que oportunidades foram deixadas de lado para a criação de mecanismos amplos e mais efetivos. Contudo, ainda que com esse lapso, vemos este debate sendo construído. 


\section{Referências bibliográficas}

BAPTISTA, Vinicius Ferreira, (2017), "Diretrizes nacionais e o descompasso na formação humanística do curso de graduação em Administração Pública da UFRRJ" Revista de Gestão e Avaliação Educacional, 6[13], p. 101-119. $\begin{array}{llll}\text { Consultado a 25.07.2019 em } & \text { a }\end{array}$ $<$ https://periodicos.ufsm.br/regae/article /view/26212.

\section{BAPTISTA, Vinicius Ferreira;} SANTOS, Wanderson Cesar, (2018), "Perspectivas de desigualdades sociais no curso de graduação em Administração Pública de uma universidade pública federal". Revista de Gestão e Avaliação Educacional, 7[14], p. 111-133. Consultado a 25.07.2019 em $<$ https://periodicos.ufsm.br/regae/article /view/29657>.

BOURDIEU, Pierre (1998), La domination masculine. Paris, Seuil.

BUTLER, Judith, (1999). Gender Trouble: Feminism and the subversion of Identity. Nova York: Routledge.
COLLINS, Patricia Hill, (1990). Black Feminist Thougth: knowledge, consciousness and the politics of empowerment. Nova York, Routledge.

Constituição da República Federativa do Brasil. Brasília: Senado Federal. Diário Oficial da União de 5.10.1988. Brasília.

CORNELL, Drucilla, (1998). At the Heart of Freedom: Feminism, Sex, and Equality. Princeton: Princeton University Press.

DAVIS, Angela Yvonne, (1983). Women, Race \& Class. Nova York: Randon House.

Decreto $\mathrm{n}^{\mathrm{o}} 7.958 / 2013$ de 13 de março de 2013. Diário Oficial da União de 14.3.2013. Brasília.

Decreto $\mathrm{n}^{\mathrm{o}} 7.393 / 2010$ de 15 de dezembro de 2010. Diário Oficial da União de 16.12.2010. Brasília.

Decreto-Lei $\mathrm{n}^{\mathrm{o}} 3.689 / 1941$ de 3 de outubro de 1941. Diário Oficial da União de 13.10.1941 e retificado em 24.10.1941. Brasília. 


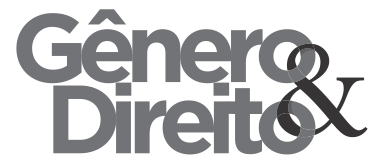

Periódico do Núcleo de Estudos e Pesquisas sobre Gênero e Direito

Centro de Ciências Jurídicas - Universidade Federal da Paraíba V. 8 - No 03 - Ano 2019

ISSN | 2179-7137 | http://periodicos.ufpb.br/ojs2/index.php/ged/index
Decreto-Lei $\mathrm{n}^{\circ} \quad 2.848 / 1940$ de 7 de dezembro de 1940. Diário Oficial da União de 31.12.1940. Brasília.

FRASER, Nancy, (1989). Unruly practices: power, discourse and gender in comtemporary social theory. Minneapolis, University of Minneapoly Press.

FRASER, Nancy, (2009). Scales of jutice: reimagining political space in a globalizing world. New York, Columbia University Press.

\section{FUNDAÇÃO PERSEU ABRAMO,} (2010). Violência contra a Mulher na Esfera Pública e Privada. São Paulo: Fundação Perseu Abramo, SESC.

HOOKS, bell, (1984). Feminist Theory: From Margin to Center. 2. ed. Nova York/Boston, South End Press.

HOULSTON, James, (2013). Cidadania insurgente: disjunções da democracia e da modernidade no Brasil. Tradução de Claudio Carina. Revisão Técnica de Luísa Valentini. 1. ed. Companhia das Letras: São Paulo.
235

Lei n ${ }^{\circ} 13.641 / 2018$ de 3 de abril de 2018.

Diário Oficial da União de 4.4.2018. Brasília.

Lei ${ }^{\circ} 13.642 / 2018$ de 3 de abril de 2018 . Diário Oficial da União de 4.4.2018. Brasília.

Lei $\mathrm{n}^{\mathrm{o}} 13.505 / 2017$ de 8 de novembro de 2017. Diário Oficial da União de 9.11.2017. Brasília.

Lei $\mathrm{n}^{\circ} 13.285 / 2016$ de 10 de maio de 2016. Diário Oficial da União de 11.5.2016. Brasília.

Lei $\mathrm{n}^{\mathrm{o}}$ 13.104/2015 de 9 de março de 2015. Diário Oficial da União de 10.3.2015. Brasília.

Lei $n^{\circ} 13.105 / 2015$ de 16 de março 2015. Diário Oficial da União de 17.3.2015. Brasília.

Lei $\mathrm{n}^{\circ} 12.015 / 2009$ de 7 de agosto de 2009. Diário Oficial da União de 10.8.2009. Brasília.

Lei $\mathrm{n}^{\mathrm{o}} 10.406 / 2002$ de 10 de janeiro 2002. Diário Oficial da União de 1.1.2002. Brasília. 
Lei $\mathrm{n}^{\circ}$ 9.099/1995 de 26 de setembro de 1995. Diário Oficial da União de 27.9.1995. Brasília.

Lei Complementar $n^{\circ}$ 80/1994 de 12 de janeiro de 1994. Diário Oficial da União de 13.1.1994. Brasília.

Lei $\mathrm{n}^{\circ} 7.210 / 1984$ de 11 de julho de 1984. Diário Oficial da União de 13.7.1984. Brasília.

OKIN, Susan Moller, (1989). Justice, Gender, and the Family. Nova York, Basic Books.

PATEMAN, Carole, (1998). The Sexual Contract. Stanford, Stanford University Press.

PHILLIPS, Anne, (2011). Gender and Culture. Oxford, Oxford, Polity.

RHODE, Deborah, (1991). Justice and Gender: Sex Discrimination and the Law. Cambridge, Harvard University Press.

SECRETARIA DE POLÍTICAS PARA AS MULHERES (SPM), (2013). Plano Nacional de Políticas para as Mulheres
WAISELFISZ, Julio Jacobo, (2015). Mapa da Violência 2015: Homicídio de mulheres no Brasil. Brasília: Faculdade Latino-Americana de Ciências Sociais.

YOUNG, Iris Marion, (1997). Intersecting Voices: Dilemmas of Gender, Political Philosophy and Policy. Princeton: Princeton Uuniversity Press.

YOUNG, Iris Marion, (2011). Responsability for Justice. Oxford,

Oxford University Press

2013-2015. Brasília: Secretaria de Políticas para as Mulheres.

(1)

